\title{
CARTAZES DO FILO: UMA CONTRIBUIÇÃO HISTÓRICA AO DESIGN GRÁFICO BRASILEIRO
}

\author{
Filo Posters: an Historic contribution to Brazilian Graphic Design.
}

\author{
DORNELES, Juliana Brandao; Especialista; \\ Faculdade Pitágoras; \\ julie_handrews@hotmail.com \\ PEREIRA,Carlos Augusto; Especialista; \\ Faculdade Pitágoras; \\ carlospereira79@yahoo.com.br \\ GOMES, Rogerio Zanetti; Mestre em Design UNESP; \\ hola@rogerioghomes.com
}

\begin{abstract}
RESUMO
Este artigo apresenta um estudo sobre os cartazes do Festival Internacional de Londrina, cujo objetivo é identificar elementos visuais marcantes e tendências gráficas, de modo a reconstruir a história do design gráfico local e nacional. A partir de uma análise baseada nos elementos e fundamentos básicos do design e nas estratégias de comunicação visual, constatou-se a forte identidade visual do Festival e a importância histórica de seus cartazes. O presente artigo caracteriza-se ainda como registro, incentivando a preservação do acervo.
\end{abstract}

Palavras-chave: design gráfico, cartaz, festival, teatro.

\begin{abstract}
This paper presents a study about the posters of Festival Internacional de Londrina, which intent is to identify important visual elements and graphical trends, in order to reconstruct the history of graphic design locally and nationally. From an analysis based on the elements and fundamentals of design and visual communication strategies, there was a strong visual identity of the Festival and the historical importance of their posters. This paper is still characterized as registration, encouraging the preservation of the collection.
\end{abstract}

Key-words: graphic design, poster, festival, theater.

\section{INTRODUÇÃo}

O Festival Internacional de Londrina - FILO - é um dos principais festivais de teatro do país. Tendo sido o primeiro não só do Brasil, mas de toda a América Latina, o Festival possui atualmente representatividade e reconhecimento nacional e internacional.

Criado em 1968 como um evento de grupos universitários locais, o Festival de Londrina cumpriu um roteiro histórico-cultural, registrando a travessia dos períodos sócio-políticos que marcaram de forma contundente as quatro últimas décadas de nossa história. Em todo esse período, o evento local transformou-se e, passo a 
passo, alcançou caráter internacional. Sempre na vanguarda, antecipando conceitos de liberdade de expressão, democracia, cidadania e globalização. (FESTIVAL INTERNACIONAL DE LONDRINA, 2006)

Mais do que promoverem o evento, os cartazes fazem parte do espetáculo e colaboram na construção de sua identidade. Não por acaso, durante cerca de cem anos o cartaz reinou soberano, como um ícone, em eventos culturais (MELO, 2005). No caso do FILO, os cartazes tiveram significativa importância na construção da identidade, exatamente por caracterizarem uma síntese de cada época e se apropriar de temas relacionados à política, às artes, à história, etc. que seriam abordados na edição do evento.

Além disso, tornaram-se uma fonte de estudos em Design Gráfico, devido à diversidade da coleção. Ao longo de mais de quatro décadas, alguns exemplares se perderam, outros se danificaram e não existem mecanismos nem organizações que garantam a preservação desses artefatos.

Nesse sentido, Cardoso (2004) ressalta a importância do conhecimento e divulgação das fontes primárias na elaboração eficaz de relatos históricos e ainda alerta para abundância de acervos brasileiros desconhecidos ou esquecidos, que correm risco de desagregação ou destruição. No sentido da construção da história do design gráfico, o autor ainda defende que "o cruzamento de dados de ordem econômica e cultural com outras informações de natureza tecnológica e artística faz-se essencial para dar sentido à diversidade de manifestações do design em diferentes contextos".

Buscado apontar a importância/contribuição que esses cartazes podem oferecer à construção da história do design gráfico local e nacional, a realização de um estudo como este, além de conferir mais visibilidade às peças, consiste num primeiro passo em direção à conservação, por meio de registro do acervo.

Com o intuito de reconhecer os elementos marcantes na linguagem visual do evento, identificar as tendências gráficas, e, assim, reconstruir a história do design gráfico londrinense e brasileiro, o presente artigo dedica-se a analisar os cartazes do FILO, levando-se em conta os elementos e fundamentos básicos do design e as estratégias de comunicação visual. Para garantir a viabilidade do projeto, devido à dimensão do acervo, foram selecionados dez cartazes, sendo dois de cada década e com intervalo médio de cinco anos entre cada um deles, a contar do primeiro, de 1968.

\section{O Cartaz}

A popularização do cartaz deu-se no final século XIX, por meio de uma série de fatores tecnológicos, como as mudanças na fabricação do papel e nos processos de impressão. No início, os cartazes continham imagens simples ou apenas texto em preto em branco, restritos a uma variedade de tipos já prontos. A invenção da litografia permitiu a impressão em grandes áreas de modo uniforme, a utilização de várias cores e tons, além do desenho de tipografias diferenciadas. Esse tipo de impressão possibilitou também edições de grande tiragem, preço vantajoso e grandes formatos.

Nas ruas das crescentes cidades do final de século XIX, os pôsteres eram uma expressão de vida econômica, social e cultural, competindo entre si para atrair compradores para os produtos e público para os entretenimentos. A atenção dos transeuntes era capturada pelo colorido dos pôsteres, que se tornou possível graças ao desenvolvimento da impressão litográfica. As ilustrações refletiam o estilo artístico da época e introduziam uma nova estética de imagens econômicas e simplificadas, decorrentes dos meios utilizados para reproduzi-las. O que Ihes dava um contexto preciso era o texto. (HOLLIS, 2000, p.115)

A princípio, o cartaz era utilizado como peça de divulgação principalmente de eventos culturais e de entretenimento. Com a sua acelerada difusão e diversificação, passou a ser o principal veículo de comunicação, promovendo de todo tipo de serviço ou produto. Nesse contexto, segundo Meggs (2009), o artista francês Jules Chéret, considerado o criador da linguagem no cartaz moderno, destacou-se por suas composições, que além de valorizar uma figura central, eram caracterizadas pela ampla utilização do campo gráfico, através de cores vivas e texturas. Entretanto, ainda conforme Meggs (2009), o artista 
que ficou mais conhecido em termos de produção de cartazes foi o francês Henri de Toulouse-Lautrec. Ele assumiu e amadureceu o estilo de Chéret, além de alcançar maior compatibilidade entre texto e imagem.

Cardoso (2004) explica que, ao longo de sua evolução, "o cartaz teve uma aplicação principalmente urbana", isso porque, "o cartaz, enquanto peça de divulgação, só faz sentido em contextos em que há o que divulgar, o que justifica a sua relativa escassez em contextos de pouca atividade".

Ao considerarmos as principais características do cartaz - imagem fixa exposta ao ar livre, dirigida ao público em trânsito, adequada à escala humana, reproduzida em série e distribuída em função de sua viabilidade econômica - fica fácil entender como esse processo aconteceu. Em tais condições, o cartaz firmou-se como um veículo de comunicação de massa visto indiscriminadamente por toda espécie de gente.

Enquanto o folheto, o rádio, a TV, etc. vão à residência do consumidor, o jornal e a revista são comprados de motus próprio, o cartaz e o luminoso são percebidos de passagem, nas vias públicas, mais ou menos casualmente. Entretanto, pelo seu tamanho e pelas cores (e o luminoso pelo fulgor) exercem impacto sobre o público e pela repetida exibição conseguem influir, fixar uma mensagem breve e veicular uma impressão. (SANT'ANNA, 2006, p.65)

Ainda levando-se em conta as características do cartaz, Hollis (2000) aponta que "o pôster, como design gráfico, pertence à categoria da apresentação e da promoção, na qual imagem e palavra precisam ser econômicas e estar vinculadas a um significado único e fácil de ser lembrado". Mello (2005) afirma também que "o projeto do cartaz exige múltiplos esforços, por vezes em direções divergentes". Pois, além de ser parte do evento ao qual se refere, é também identidade visual e, por fim, uma peça promocional.

A função do cartaz, portanto, não se encerra em identificar ou divulgar determinado produto ou evento. Ao longo dos anos, o cartaz mostrou-se capaz de registrar movimentos de seu tempo, principalmente pelas características estéticas empregadas na construção da mensagem. Mais do que isso, segundo Moles (1970) "o cartaz como mensagem da sociedade para o indivíduo não é estática; pela sua repetição em múltiplas cópias postas em diferentes lugares, o cartaz se decalca, pouco a pouco no cérebro dos membros da sociedade para aí se constituir num elemento da cultura".

A Bienal de São Paulo é o mais emblemático evento ligado ao cartaz no Brasil. Ela deu lastro institucional às primeiras manifestações da linguagem gráfica moderna entre nós, nos idos de 1951, ano de sua primeira edição. Desde o início os cartazes eram a peça-chave para conformar a identidade de cada edição. A história da Bienal pode ser contada pela seqüência de seus cartazes. (MELO, 2005, p. 43)

Assim, podemos concluir que o trajeto do design gráfico e, consequentemente, dos cartazes, está intimamente relacionado à história e à cultura de cada lugar. Mas é necessário dizer que o significado atribuído ao cartaz enquanto mensagem depende essencialmente do reconhecimento dos elementos visuais gráficos que o constitui, da relação entre esses elementos e, especialmente, da maneira como o espectador perceberá esse estímulo (DONDIS, 1997). Utilizando a definição de Lupton (2008), as articulações dos elementos em mensagens visuais funcionam da mesma forma como nas textuais - através da linguagem: "enquanto um dicionário estuda isoladamente palavras específicas, as mesmas ganham vida no contexto fluido da escrita".

Sejam quais forem os critérios adotados para análise, primeiramente é preciso identificar e examinar os componentes individuais do processo visual em sua forma mais simples: os elementos visuais básicos. Eles constituem a caixa de ferramenta para qualquer tipo de acontecimento visual: o ponto, a linha, a forma, a direção, o tom, a cor, a textura, a proporção, a dimensão e o movimento. A manipulação desses elementos, por meio de técnicas ou estratégias de comunicação visual, torna possível a elaboração das mais variadas mensagens visuais, com suas características e objetivos distintos. 
Dondis (1997) ressalta que "são muitas as técnicas que podem ser aplicadas na busca de soluções visuais". Essas estratégias são apresentadas como polaridades, mas podem, e devem, variar sua intensidade de acordo com o caráter e os objetivos da mensagem. A autora defende ainda que $o$ contraste - em contraposição à harmonia, seu oposto -, é a mais dinâmica das técnicas visuais, pois nos permite entender com maior precisão, pelo método de comparação, todas as outras polaridades.

No livro Sintaxe da Linguagem Visual, da mesma autora, são listadas algumas das técnicas mais usadas e de fácil identificação, de modo a enfatizar a oposição entre os pares: contraste e harmonia; instabilidade e equilíbrio; assimetria e simetria; irregularidade e regularidade; complexidade e simplicidade; fragmentação e unidade; profusão e economia; exagero e minimização; espontaneidade e previsibilidade; atividade e estase; ousadia e sutileza; transparência e opacidade; variação e estabilidade; distorção e exatidão; profundidade e planura; justaposição e singularidade; acaso e seqüencialidade; agudeza e difusão; episodicidade e repetição (DONDIS, 1997).

Com conhecimento prévio sobre os elementos básicos e as estratégias de comunicação visual, cabe enfatizar a importância da composição na solução dos problemas visuais, pois os significados e objetivos das mensagens são resultados diretos das decisões compositivas, que têm fortes implicações nas percepções do espectador.

\section{Diretrizes para análise}

Para este estudo, entende-se que as peculiaridades do cartaz enquanto peça gráfica configura um assunto que deve ser pensado de maneira mais ampla, ultrapassando os limites do design. Assim, a análise se desenvolverá em suas dimensões técnicas, estéticas e simbólicas. Mas, mais do que isso, acredita-se que, conforme citado anteriormente, esse tipo de artefato tem o poder de, em determinados momentos, fornecer informações sobre história da sociedade e do design gráfico. E, é nesse sentido que incluímos, em cada uma das análises, uma breve contextualização, apresentando o momento que o Festival atravessava e o ambiente cultural em que o cartaz foi desenvolvido.

\section{8 - Inauguração do Festival}

Figura 1-Cartaz do 1을 Festival Universitário

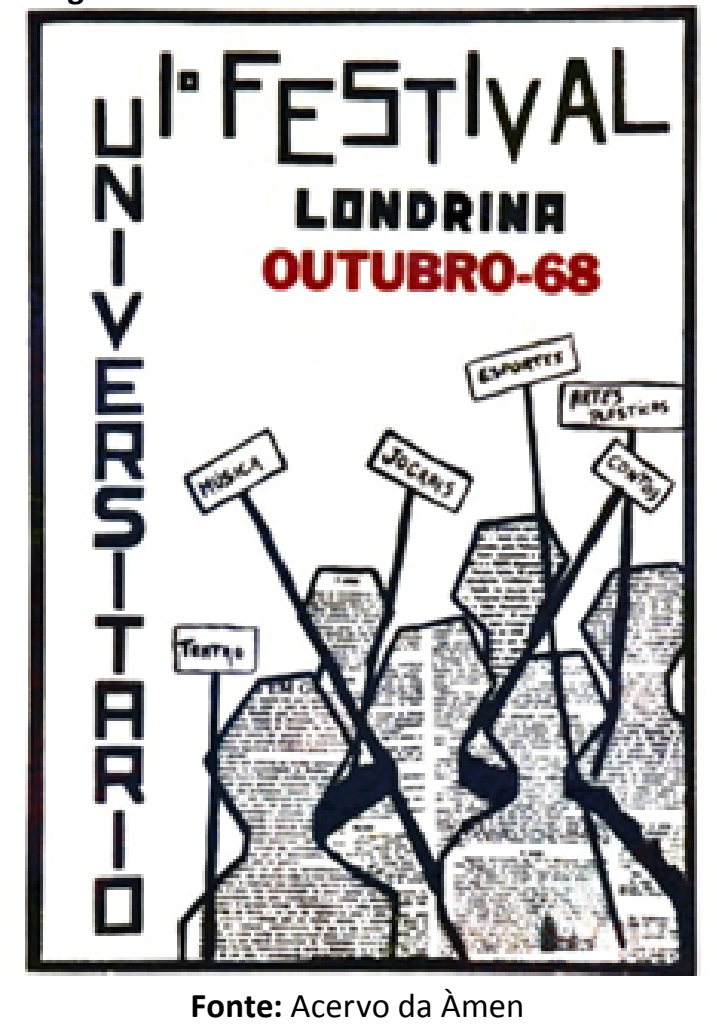


A primeira edição do FILO aconteceu em meio a um cenário político turbulento. Enquanto em todo o Brasil o golpe militar ecoava e os estudantes eram reprimidos, o então Festival Universitário de Londrina surgia como uma forma driblar as proibições, sintonizar-se com as mudanças ao redor do mundo e testar potencial cultural da cidade.

Segundo Hollis (2000), no mundo toda a situação era a mesma. Revoltados com eventos como a Guerra do Vietnã a cultura capitalista e o autoritarismo do estado - que culminaram na revolta estudantil francesa, em 1968 em Paris - estudantes e grupos de protesto de muitos países dominaram, no final dos anos 60 , as técnicas de impressão para se expressarem através de pôsteres. A principal técnica utilizada era a serigrafia, na maioria das vezes em preto e branco, resultando em imagens simples e impactantes, cujo acabamento não era dos mais refinados.

Como reflexo desses acontecimentos, o cartaz do 10 Festival Universitário valia-se do mesmo tipo de linguagem tanto nas cores, quanto nas figuras humanas em manifestação. Entretanto, nas placas empunhadas pelos indivíduos, em vez de palavras de rebelião, foram escritas as atividades que o Festival exibiria. As características artesanais provenientes da serigrafia são realçadas pela tipografia produzida por letreiramento e pela aplicação de textura de jornal nas silhuetas, referindo-se à omissão das pessoas diante da ditadura e reforçando o caráter político do acontecimento.

A espontaneidade, configurada pela aparente falta de planejamento na peça, exalta a emoção, impulsiva e livre. Da mesma maneira, a atividade se dá na sugestão de movimento através das placas de "protesto" inclinadas no ar. Somando-se a essas características, há ainda a instabilidade da composição, que completa o sentido da mensagem em um período de grande tensão e movimentação política.

\section{3 - Festival universitário: de multidisciplinar a teatral}

Figura 2 - Cartaz do 6으 Festival Universitário

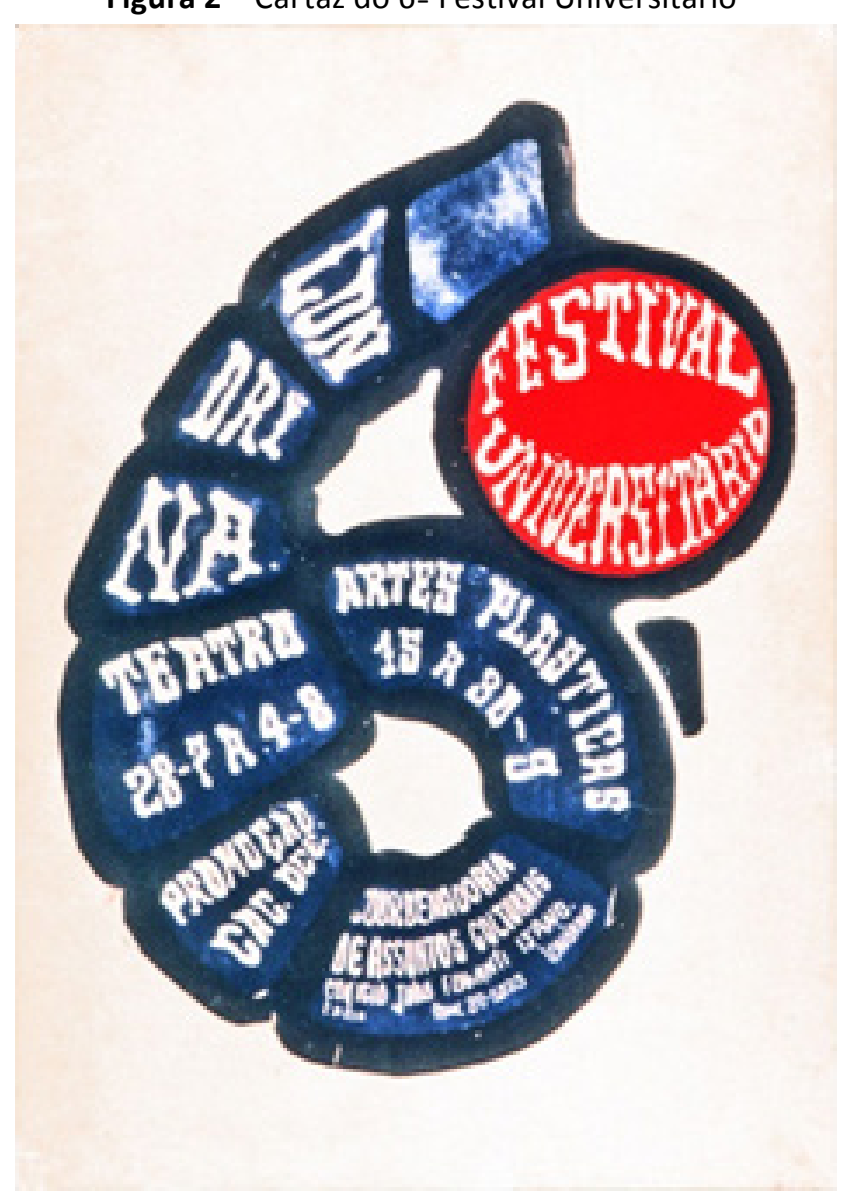

Fonte: Acervo da Àmen 
No princípio, o Festival Universitário tinha um caráter múltiplo, capaz de reunir diferentes manifestações artísticas. As atividades aconteciam sob a forma de concursos, predominando eventos que envolviam Música Popular Brasileira. Porém, em 1970, os concursos de música popular perderam força tanto na qualidade das composições quanto no interesse do público. Assim, quando a recémcriada Universidade Estadual de Londrina assumiu sua produção, em 1971, o Festival tornou-se uma mostra de teatro, contando com análises críticas das peças e curso para formação de atores, entre outros. Dessa maneira, iniciou-se o desenvolvimento do teatro amador de Londrina e região e, em 1972, o Festival passou a chamar-se Festival Universitário de Teatro.

Para Nitis Jacon (2010), o Festival de 1973 representou um marco no sentido da organização e da articulação de movimentos mais ambiciosos e abrangentes. Foram desenvolvidos, no período, diversos projetos culturais junto à comunidade, debates e atividades acadêmicas, através da continuidade do Congresso de Teatro. $O$ evento contou também com a participação de grupos de outros estados, abrindo caminho para a mostra nacional.

No cartaz, que tem como tema central o numeral seis, em alusão à edição do evento, a singularidade é predominante. A forma trabalhada do número - enfatizada pelo fundo branco - faz referência a uma obra de arte e ao caráter mais intelectual que o Festival havia assumido. Além disso, os fragmentos em que o numeral é dividido abrigam e hierarquizam as informações orientando a sequência de leitura. Por fim, a tipografia utilizada - produzida por letreiramento - é semelhante às desenvolvidas por Victor Moscoso em seus pôsteres psicodélicos em meados dos anos 60 .

O nome mais conhecido do grupo de designers psicodélicos da Califórnia, e o único com formação em arte, era Victor Moscoso, que estudava as cores em Yale com Josef Albers, ex-professor da Bauhaus. Moscoso combinava efeitos de vibração óptica obtidos por meio das cores som letras formais que ele tornava quase ilegíveis através de uma total equivalência entre elementos positivos e negativos: o espaço existente entre as letras e dentro delas era contrabalanceado pelas próprias letras, da mesma maneira como cores adjacentes contrastam entre si com igual intensidade. (HOLLIS, 2000, p.98)

\section{7 - O Festival, a ditadura e o estilo suíço}

Figura 3 - Cartaz do X Festival Universitário de Teatro de Londrina

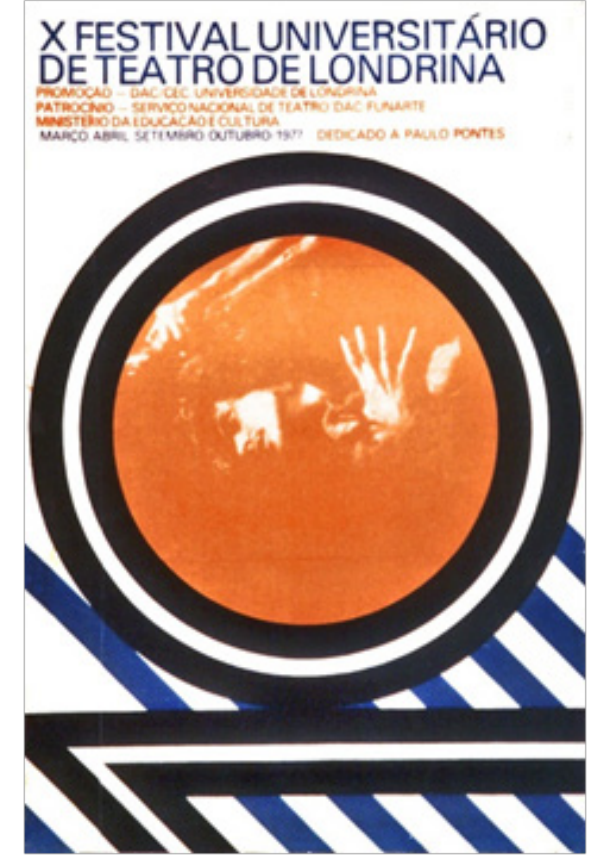

Fonte: Acervo da Àmen 
Em 1977, o FILO continuava sob responsabilidade da UEL em conjunto com algumas entidades do teatro local. Porém, o apoio da Universidade não era dos melhores e o Festival corria o risco de chegar ao fim. Somando-se a isso, o regime de ditadura permanecia e, além dos espetáculos terem de passar pela censura visual, os processos burocráticos retardaram a divulgação, prejudicando toda a programação. Mesmo assim, o saldo do X Festival foi positivo em número e qualidade das atividades e em público (JACON, 2010).

O cartaz da décima edição do FILO, por sua vez, explorava o estilo suíço, que, segundo Hollis (2000), em 1970, era "o estereótipo de design gráfico". Usado no mundo inteiro, se caracterizava "pela ausência de ornamentos, por espaços brancos, tipos sem serifa e uso de grade" (HOLLIS, 2000). Predominantemente simples, a peça gráfica é constituída por linhas retas (dispostas como textura ao fundo), formas geométricas e tipografia sem serifa, que conferem à composição regularidade e unidade - características marcantes do estilo. A harmonia é intensificada pela utilização de cores complementares (laranja e azul) em contraponto com a predominância da cor branca.

Um ponto interessante a se destacar é que o designer se apropria da forma tipográfica do número 10 para, além de identificar a edição do evento, compor e enfatizar uma forma que lembra uma lente fotográfica retratando uma cena teatral, o que poderia estar associado à censura acirrada pela qual os espetáculos que seriam exibidos estavam sujeitos. As cores, mais uma vez, realçam o sentido da mensagem, já que a cor quente está aplicada sobre a cena - indicando atividade, emoção, comunicação - enquanto no restante da composição predominam as cores frias e neutras da repressão.

\section{3 - Impressão tipográfica versus impressão offset}

Figura 4 - Cartaz do XV Festival Universitário de Teatro de Londrina

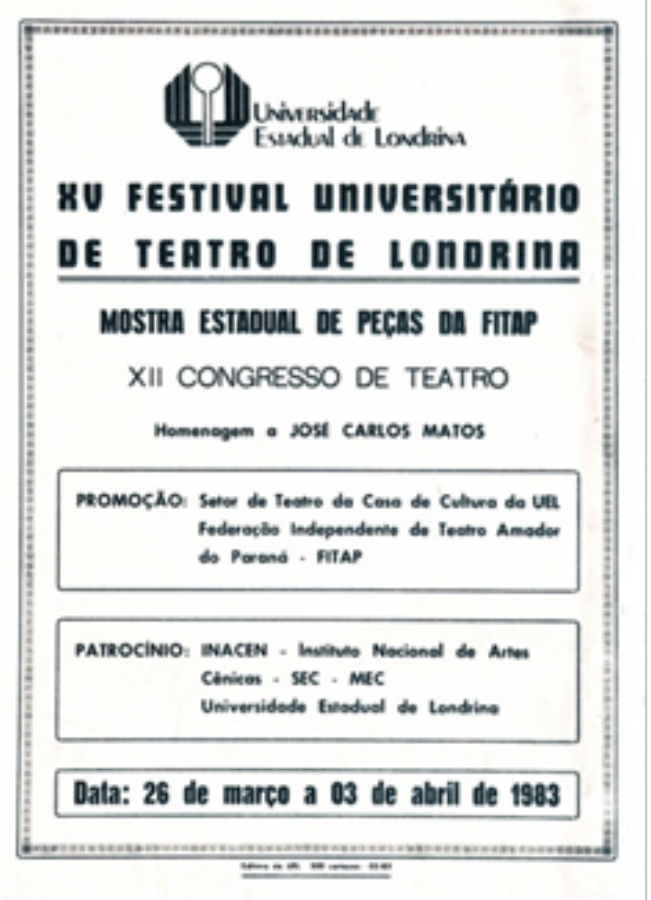

Fonte: Acervo da Àmen

O início da década de 80 no Brasil foi marcado pelo gradual relaxamento do regime autoritário. Porém, para a realidade do Festival Universitário de Teatro de Londrina, que já estava em sua segunda década, esse acontecimento não se fazia sentir: persistia a ação da estrutura repressiva e mantinha-se a postura abusiva. Isso talvez justifique a produção de um cartaz simples e com menos requinte técnico em relação aos anteriores. As diretrizes do Festival, entretanto, permaneciam as mesmas, com uma atuação social focada no desenvolvimento e propagação da arte teatral junto à comunidade (JACON, 2010). 
Como mencionado acima, o cartaz da 15a edição do evento não contava com o mesmo apuramento gráfico de cartazes anteriores. Claramente produzido por impressão com tipos de metal, o artefato destaca-se pela multiplicidade no número de famílias tipográficas empregadas e nas diferentes características de cada uma delas - em suas estruturas, proporções e formas.

Bringhurst (2005) destaca que "a impressão tipográfica acomoda as letras dentro do papel, mas a impressão offset as dispõe na superfície". Nesse cartaz, percebem-se fortes características e restrições resultantes do modo de produção. $O$ fato de conter informações exclusivamente textuais, por exemplo, evidencia o modo de produção exclusivamente tipográfico, que frequentemente não faz uso de outros elementos que não os caracteres.

\section{8 - I Mostra Latino-Americana, o Festival torna-se internacional}

Figura 5 - Cartaz de 20 anos do Festival Universitário de Teatro de Londrina

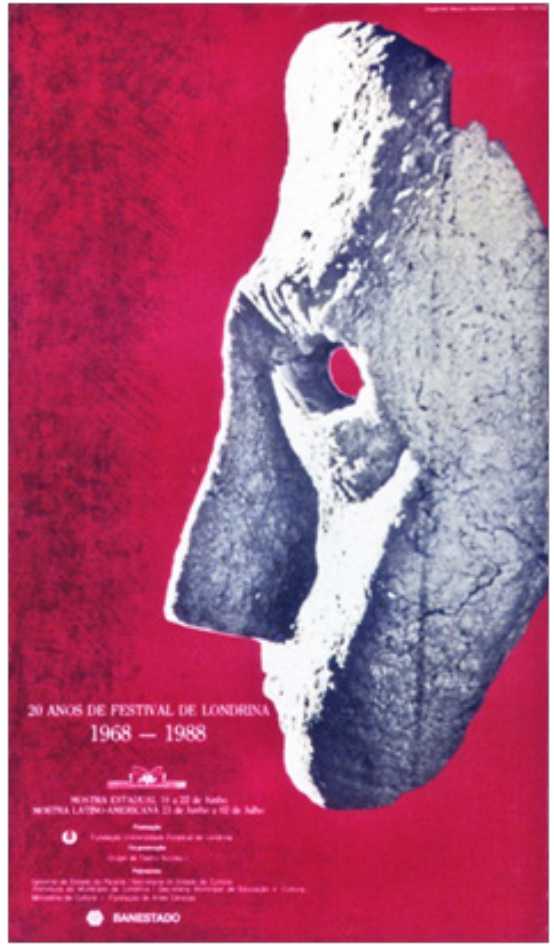

Fonte: Acervo da Àmen

No final da década de 80, em meio à abertura democrática, o Festival Universitário de Teatro adapta-se aos novos tempos e introduz a I Mostra Latino-Americana, melhorando consideravelmente a qualidade do evento. Mais do que acordos de comércio, o intercâmbio cultural é a maneira mais produtiva de conhecermos e de trocarmos experiências e emoções com nossos vizinhos (FESTIVAL INTERNACIONAL DE LONDRINA, 1997).

O uso da máscara como elemento cênico surgiu no teatro grego, como uma maneira de acentuar a expressão facial e amplificar a voz do ator - o artefato possuía uma espécie de alto-falante em miniatura adaptado à boca. Ao longo dos séculos, a máscara esteve presente em várias culturas, como elemento de comunicação e, ainda hoje, as máscaras são objeto de estudo e trabalho de diversas companhias teatrais em todo o mundo. Graças ao intercâmbio cultural, a máscara grega foi reconhecida desde o início como símbolo máximo do teatro.

Levando-se em conta a internacionalização do Festival, a máscara foi utilizada como elemento principal na elaboração do cartaz. Utilizada com segurança, através da técnica de singularidade, a máscara representa a força e solidez de 20 anos de Festival. A aparente estase é perturbada pelo exagero nas dimensões do elemento principal, evidenciando a imperfeição de sua textura e aproximando o espectador em termos sinestésicos. A mensagem adquire força na composição assimétrica e instável, 
e seu sentido é completado pelo emprego da cor vibrante no fundo em contraste com a neutralidade da máscara.

\section{3 - A complementaridade entre Mostra Regional e Festival Internacional}

Figura 6 - Cartazes da Mostra Regional de Teatro e do Festival Internacional de Londrina de 1993
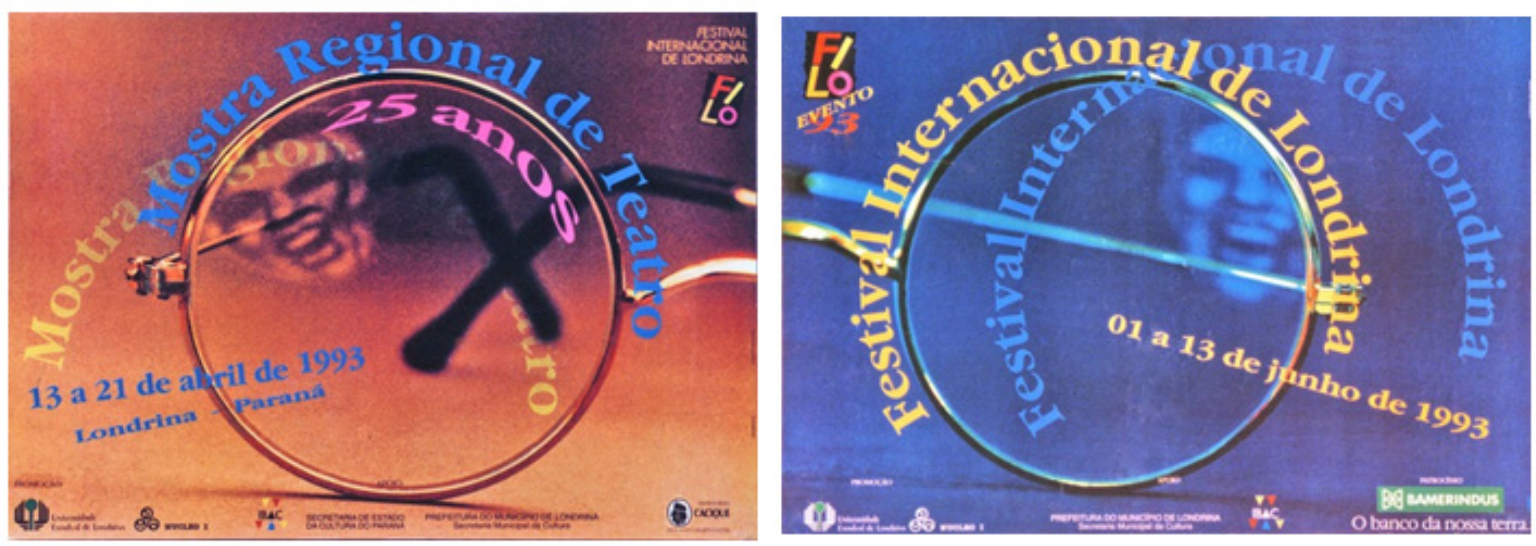

Fonte: Acervo da Àmen

Em 1990, da unificação do Festival Universitário de Teatro e da Mostra Latino-Americana surge o Festival Internacional de Londrina - FILO. Nessa altura, o Festival já estava estabelecido, colocandose como o maior do país, e Londrina caracterizava-se como único pólo alternativo capaz de promover cultura fora do eixo Rio - São Paulo (FESTIVAL INTERNACIONAL DE LONDRINA, 1997). A partir de 1992, todos os cartazes passaram a ser identificados com um logotipo do evento, cuja estrutura - uma sigla em itálico - deve-se a um artifício utilizado com certa frequência em cartazes anteriores: a aplicação de tipos inclinados apenas nas iniciais do nome do Festival.

Uma eventualidade interessante é que, por algumas poucas vezes, surgiram, nos cartazes do FILO, textos com direções não convencionais, entre eles, os cartazes - da Mostra Regional de Teatro e do Festival Internacional de Londrina - de 1993. Segundo Meggs (2009), "à medida que os computadores e seus programas se tornaram mais poderosos, foi possível uma nova elasticidade espacial na tipografia e nas imagens". Hollis (2000) diz ainda que "com computadores, os designers podiam gerar relações de significado complexas por meio de superposições e da disposição em 'camadas' de elementos de texto e imagem, em vez de precisar vinculá-las vertical e horizontalmente na grade". Nos cartazes de 1993, tal prática tinha o propósito de retratar uma das principais características das manifestações teatrais: o movimento.

A exceção aberta neste momento, com a apresentação dos dois cartazes produzidos no ano de 1993, justifica-se na marcante interação entre eles. A primeira vista, destaca-se o fato de que, dispostos lado a lado, eles formam a imagem única de uns óculos, quase como um convite à apreciação dos espetáculos que compunham a Mostra e o Festival, respectivamente. Outra demonstração da complementaridade e entre as peças, são as imagens compostas em cores complementares - cores quentes para a mostra regional, mais próxima, e cores frias para o festival internacional, mais distante e profissionalizado. Tudo isso traduz uma mensagem de que, apesar de se tratar de dois eventos diferentes, eles fazem parte de um mesmo movimento, partem das mesmas diretrizes: traçam caminhos distintos, mas em um aspecto mais amplo, se completam formando uma coisa só.

\section{8 - Elementos de apoio em cena}

Figura 7 - Cartaz do Festival Internacional de Londrina de 1998 


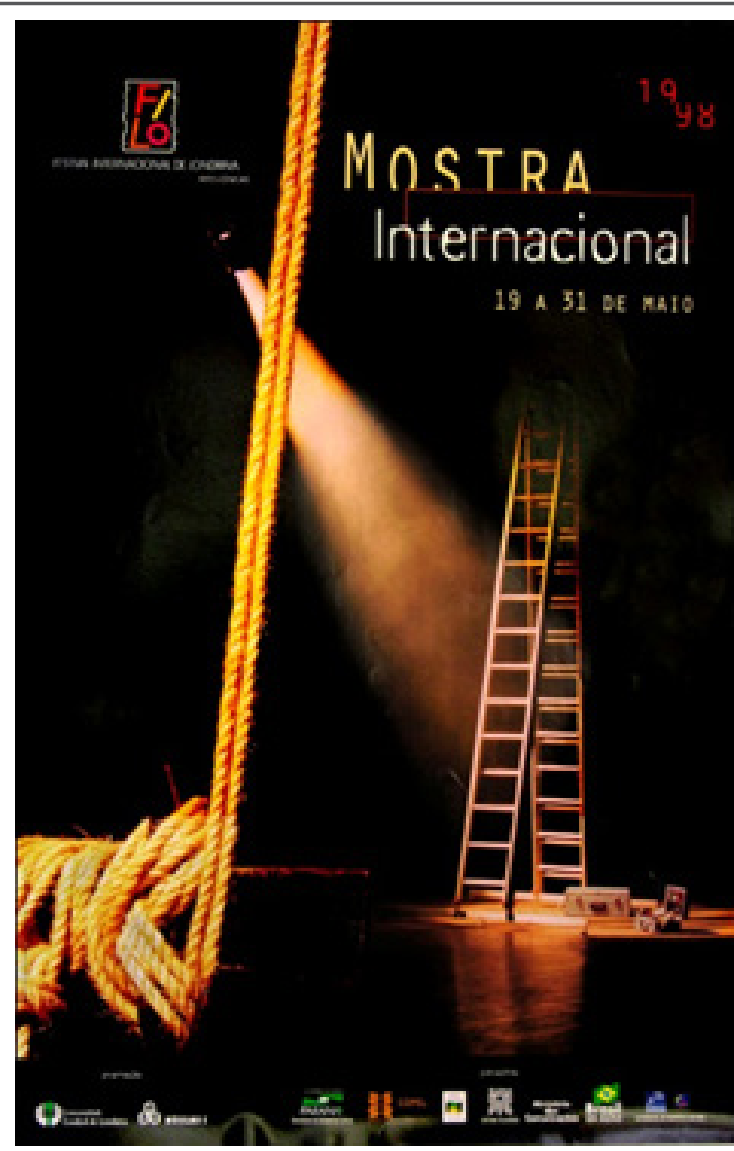

Fonte: Acervo da Àmen

Em 1997, o FILO, que já atingira sua maturidade, completara 30 anos e a comemoração mereceu o lançamento de um livro sobre sua história. No ano seguinte, com o alargamento do espaço democrático, a curadoria passava a focar a diversidade das tendências estéticas e das práticas pedagógicas das escolas de teatro. Era importante o intercâmbio de técnicas e conhecimento entre os grupos, provenientes de várias partes do mundo e pertencentes a diversas etnias. A construção cênica foi um conceito bastante explorado nas atividades referentes ao evento.

Em Jacon (2010) encontra-se uma justificativa às peças de divulgação: “O cartaz e os programas desse Festival prestavam justa homenagem àqueles que, nos bastidores, 'sem gestos dramáticos nem exposição, funcionam como peças-chave da realização teatral: técnicos, cenógrafos, marceneiros, operadores, diretores técnicos, equipes de produção'”.

Conforme mencionado acima, na comemoração dos 30 anos de Festival, o universo das artes cênicas foi mais uma vez abordado. O cartaz foi criado a partir dos elementos empregados na construção do cenário no teatro, fazendo alusão ao trabalho que se tem na preparação de um espetáculo. Como consequência do jogo de luz e sombra - que confere profundidade à imagem - e da utilização de poucos elementos, o artefato revela-se simples e objetivo no que diz respeito à criação da atmosfera teatral. Além disso, o equilíbrio na composição - proporcionado pela distribuição de elementos em diferentes planos e escalas -, em complemento com a predominante estase da imagem, torna o material sóbrio e de muito bom gosto.

\section{4 - Composição e identidade atualmente consolidada}

Figura 8 - Cartaz do Festival Internacional de Londrina de 2004 


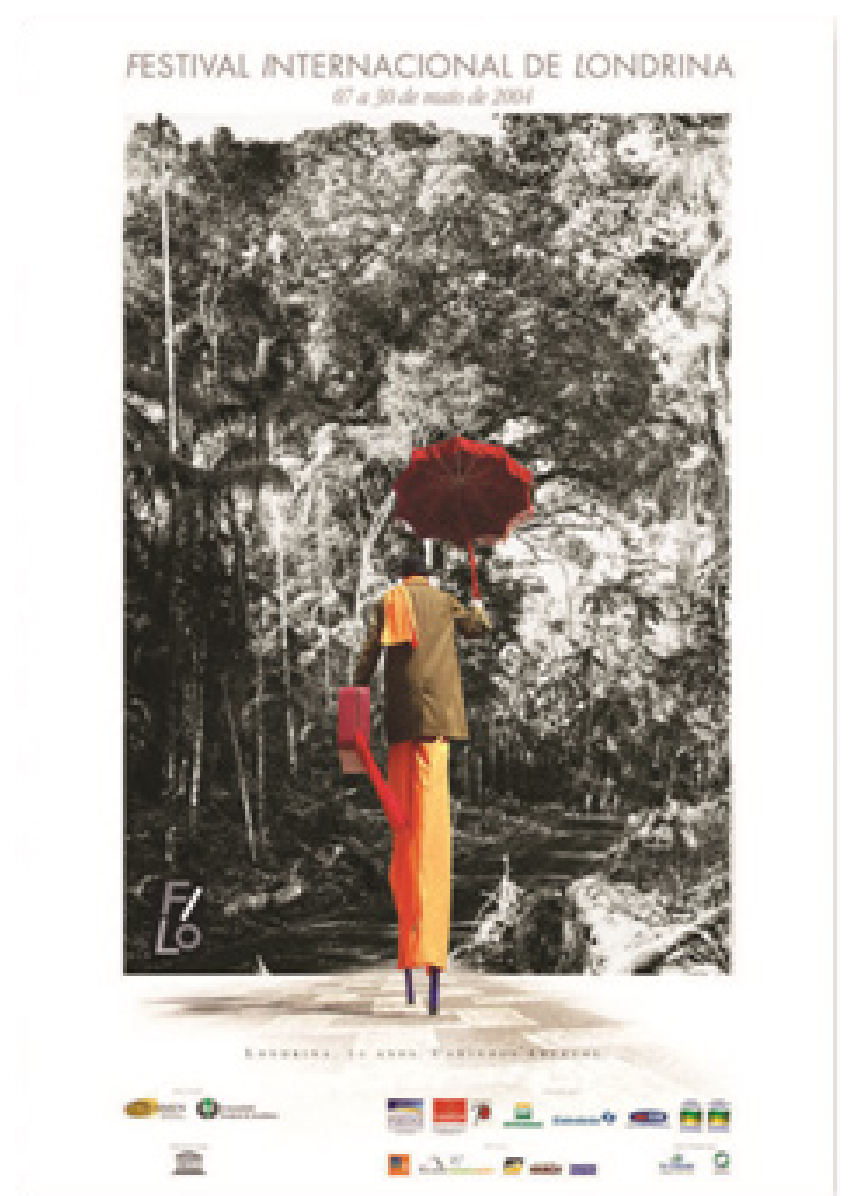

Fonte: Acervo da Àmen

Em 2004, Londrina completava seus 70 anos. O FILO, 37 anos, ou seja, mais da metade da história da cidade. A bela fotografia dos primórdios da colonização faz contraponto com o personagem em perna de pau, incorporado por Paulo Braz, um dos mais constantes e leais membros da comunidade do FILO. [...] Sua presença na foto tem valor simbólico: o olhar em direção ao passado não tão distante e a cabeça prenhe de sonhos e determinação na prospectiva de um futuro digno da audácia dos pioneiros. (FESTIVAL INTERNACIONAL DE LONDRINA, 2008)

Os 70 anos de Londrina foram comemorados com grande intensidade pelos dirigentes e por toda a comunidade londrinense. O FILO, como um importante evento da cidade, também aderiu às comemorações. Assim, em 2004, o assunto em foco no cartaz do Festival foi a volta no tempo que o teatro proporciona, bem como o reencontro de Londrina com as artes cênicas. A utilização de espaços abertos e a aproximação do público com o meio ambiente foram igualmente expressivas nessa edição do evento.

Desde o ano de 2000, a equipe da Visualitá Criação Visual, responsável pelo desenvolvimento das peças de divulgação do Festival, vinha utilizando uma estrutura simples e objetiva na composição dos cartazes. Era uma espécie de grid constituído por uma borda branca, que delimitava a área para aplicação dos elementos fixos do cartaz - como nome, data e patrocinadores do evento -, enquanto a área central ficava reservada para a abordagem do tema escolhido.

Elaborado nessa estrutura, o cartaz do FILO de 2004 enfatiza, no espaço reservado à imagem, a figura colorida do palhaço de perna de pau em contraposição ao cenário da floresta monocromática e estática, fazendo uma referência ao retorno no tempo. Além do contraste de cores, a expressividade da imagem é ressaltada pelo distanciamento entre figura e fundo, através da quebra da monotonia da imagem de fundo pela verticalidade da figura central em movimento. 
Figura 9 - Cartaz de 40 anos do Festival Internacional de Londrina

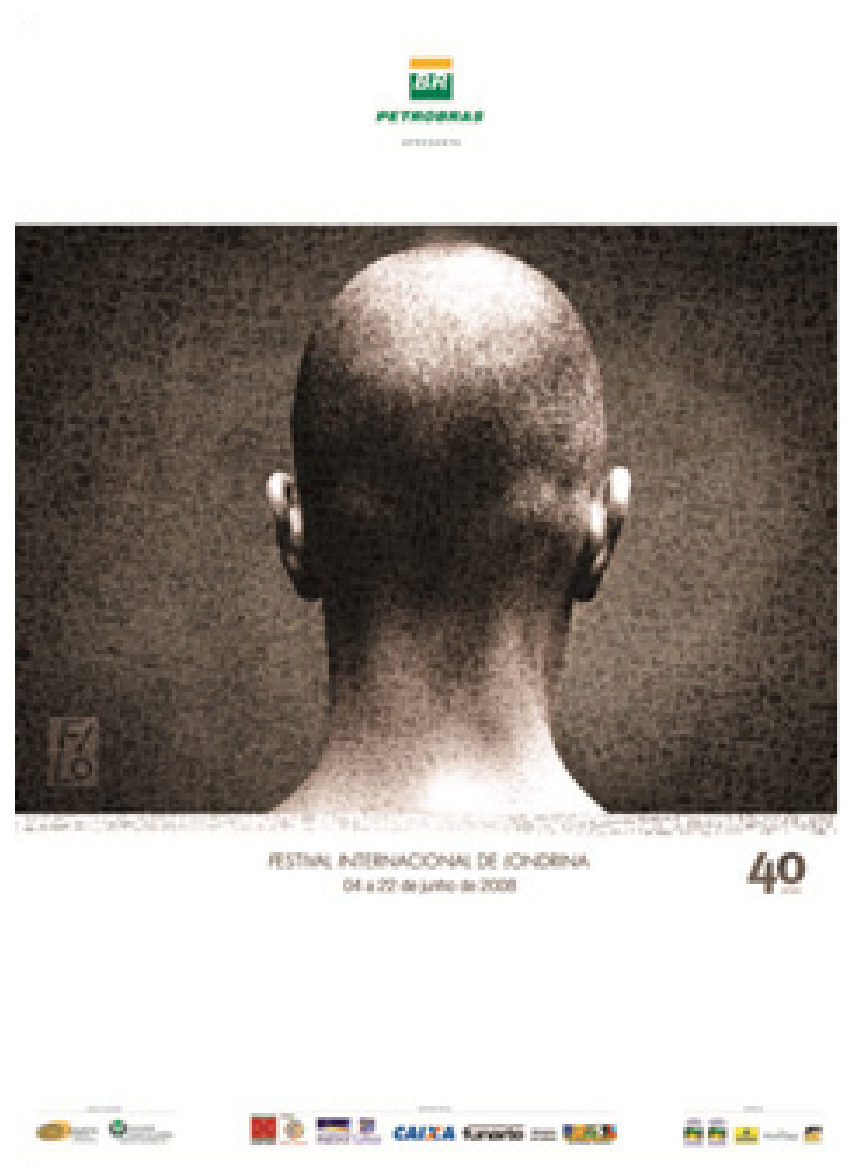

Fonte: Acervo da Àmen

Ao longo de quatro décadas, o Festival Internacional de Londrina desenvolveu e consolidou uma característica marcante: de profundo respeito pela diversidade cultural que é um dos eixos da identidade brasileira. Assim, o FILO contribuiu, e muito, para a difusão e a democratização cultural em Londrina, além de formar novas platéias e promover a reflexão sobre o que é feito no Brasil e no mundo (FESTIVAL INTERNACIONAL DE LONDRINA, 2008).

A preocupação sociocultural do FILO e seu reconhecimento nos panoramas nacional e internacional estão expressos no cartaz de 40 anos através de uma cabeça sobreposta por símbolos. A cabeça representa inteligência, bom senso, instrução, e até mesmo o espectador em si; enquanto os signos, impregnando toda a imagem, são as marcas que o Festival tem deixado ano após ano. Toda a composição é pensada de modo a transmitir estabilidade (recorte horizontal da imagem), tranquilidade (predominância da cor branca e tons menos saturados), estaticidade (ausência de movimento na imagem central) e sutileza (aplicação discreta do logotipo e das informações adicionais do cartaz).

\section{CONSIDERAÇÕES FINAIS}

A análise de 10 dos cartazes levantados nesta pesquisa proporcionou constatações e conclusões interessantes. Como não poderia deixar de ser, a amostra de cartazes não é homogênea. Há pontos mais notáveis que outros, em que a mensagem transmitida é mais consistente. Em contrapartida, é imperativo reconhecer que a história e a identidade do FILO estão estreitamente ligadas a seus cartazes: em determinados momentos, as peças conseguem traduzir com clareza os acontecimentos políticos e culturais de sua época. O que, de certa forma, conferiu aos cartazes, ao longo dos anos, importância e atenção, tornando-o a principal peça de divulgação do evento.

Apesar dos indícios de que os eventos culturais movimentam-se em direção aos sistemas de 
identidade visual, em detrimento dos pôsteres como peça de divulgação, esses designs ainda mantêm uma proximidade com o público a que se direciona, especialmente no caso de eventos culturais. Isso porque, além de se relacionar à escala do corpo, o cartaz tem uma história e uma linguagem próprias. Enquanto mídia ele apresenta-se silencioso, dependendo do genuíno interesse do leitor para cumprir sua função, principalmente quando comparado às mídias eletrônicas ou de grande formato e o bombardeio de informações por elas provocadas. A essas características soma-se o aspecto artístico, cultivado e fortalecido desde sua popularização, no final do século XIX, através das produções de artistas como Jules Chéret e Henri de Toulouse-Lautrec.

Com relação aos fatores sintáticos da análise, pode-se perceber os níveis de complexidade presentes nas manifestações visuais. E, esta complexidade é determinada pelo domínio dos elementos, fundamentos e estratégias de comunicação visual. Fatores como estes despertam, substanciam e direcionam a leitura do espectador. Agregando e trabalhando essas variáveis nos cartazes, o FILO conseguiu estabelecer uma identidade visual forte, capaz de ser reconhecida de imediato por todos aqueles que estão familiarizados com ele.

Reconhecendo a importância de uma análise desse tipo [de cartazes], o presente estudo tem intenção de contribuir para o desenvolvimento do Design Gráfico na cidade de Londrina, conservando um importante trabalho que vem sendo desenvolvido há mais de 40 anos sem o devido registro.

\section{REFERÊNCIAS}

BRINGHURST, Robert. Elementos do Estilo tipográfico. Tradução de André Stolarski. São Paulo: Cosac Naify, 2005.

CARDOSO, Rafael. Uma introdução à história do design. São Paulo: Edgard Blücher, 2004.

DONDIS, Donis A. Sintaxe da Linguagem Visual. 2ª ed. São Paulo: Martins Fontes, 1997.

FESTIVAL INTERNACIONAL DE LONDRINA. 30 anos de Festival. Londrina: Universidade Estadual de Londrina, 1997.

A História do FILO. Festival Internacional de Londrina. Londrina, 2006. Disponível em: < http://www.filo.art.br/2006/historia.php >. Acessado em: 28 de abril de 2009.

. Filo 40 anos - Registro Histórico. Londrina: FILO, 2008.

HOLLIS, Richard. Design gráfico: uma história concisa. Tradução de Carlos Daudt. São Paulo: Martins Fontes, 2000.

JACON, Nitis. Memória e recordação: Festival Internacional de Londrina - 40 anos. Londrina: Midiograf, 2010.

LUPTON, Ellen \& PHILLIPS, Jennifer Cole. Novos Fundamentos do Design. Tradução de Critian Borges. São Paulo: Cosac Naify, 2008.

MEGGS, Philip B. História do Design Gráfico. São Paulo: Cosac Naify, 2009.

MELO, Chico Homem de. Signofobia. São Paulo: Edições Rosari, 2005.

MOLES, Abraham. O cartaz. São Paulo: Editora Perspectiva, 1974.

SANT'ANNA, Armando. Propaganda: teoria, técnica e prática. 7ạ ed. São Paulo: Thomson Learning Edições, 2006. 